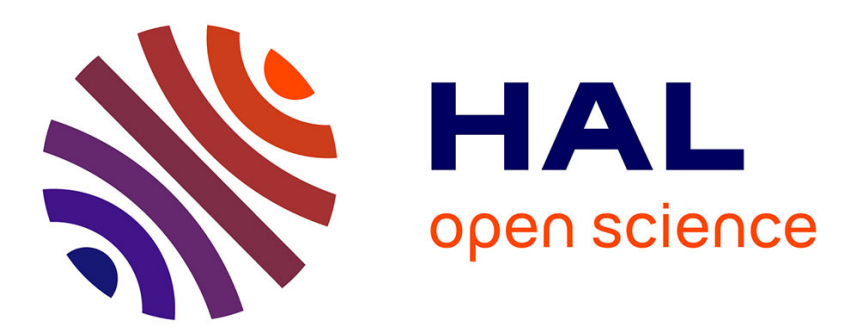

\title{
Ordering of adsorbed species on quasicrystal surfaces
}

Joseph Anthony Smerdon, Lisa H Wearing, Joseph Parle, Lydie Leung, Hem

Raj Sharma, Julian Ledieu, Ronan Mcgrath

\section{To cite this version:}

Joseph Anthony Smerdon, Lisa H Wearing, Joseph Parle, Lydie Leung, Hem Raj Sharma, et al.. Ordering of adsorbed species on quasicrystal surfaces. Philosophical Magazine, 2008, 88 (13-15), pp.2073-2082. 10.1080/14786430801914920 . hal-00513865

\section{HAL Id: hal-00513865 \\ https://hal.science/hal-00513865}

Submitted on 1 Sep 2010

HAL is a multi-disciplinary open access archive for the deposit and dissemination of scientific research documents, whether they are published or not. The documents may come from teaching and research institutions in France or abroad, or from public or private research centers.
L'archive ouverte pluridisciplinaire HAL, est destinée au dépôt et à la diffusion de documents scientifiques de niveau recherche, publiés ou non, émanant des établissements d'enseignement et de recherche français ou étrangers, des laboratoires publics ou privés. 


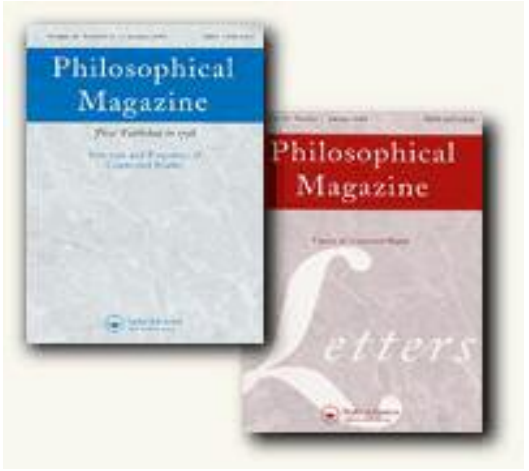

Ordering of adsorbed species on quasicrystal surfaces

\begin{tabular}{|r|l|}
\hline Journal: & Philosophical Magazine \& Philosophical Magazine Letters \\
\hline Manuscript ID: & TPHM-07-Oct-0280.R1 \\
\hline Journal Selection: & Philosophical Magazine \\
\hline Duthor: & 19-Dec-2007 \\
\hline Complete List of Authors: & $\begin{array}{l}\text { Smerdon, Joseph; The University of Liverpool, Physics } \\
\text { Wearing, Lisa; The University of Liverpool, Physics } \\
\text { Parle, Joseph; The University of Liverpool, Physics } \\
\text { Leung, Lydie; The University of Liverpool, Physics } \\
\text { Sharma, Hem; The University of Liverpool, Physics } \\
\text { Ledieu, Julian; Ecole des Mines, LSG2 M, CNRS UMR 7584 } \\
\text { McGrath, Ronan; The University of Liverpool, Physics }\end{array}$ \\
\hline Keywords: & $\begin{array}{l}\text { quasicrystalline alloys, quasicrystals, scanning probe microscopy, } \\
\text { STM, surfaces }\end{array}$ \\
\hline Keywords (user supplied): & quasicrystalline alloys, quasicrystals, scanning probe microscopy \\
\hline $\begin{array}{l}\text { Note: The following files were submitted by the author for peer review, but cannot be converted } \\
\text { to PDF. You must view these files (e.g. movies) online. }\end{array}$ \\
\hline \hline \begin{tabular}{l} 
Quasi25McGrathRevised.tex \\
\hline
\end{tabular}
\end{tabular}

\section{\) ScholarONE" \\ Manuscript Central}


Philosophical Magazine,

Vol. 00, No. 00, DD Month 200x, 1-9

\title{
Ordering of adsorbed species on quasicrystal surfaces
}

\author{
J.A. SMERDON ${ }^{1}$, L.H. WEARING ${ }^{1}$, J. PARLE ${ }^{1}$, L. LEUNG ${ }^{1 \dagger}$, \\ H.R. SHARMA ${ }^{1}$, J. LEDIEU ${ }^{2}$, R. MCGRATH ${ }^{1 \ddagger}$, \\ ${ }^{1}$ Department of Physics and Surface Science Research Centre, \\ The University of Liverpool, Liverpool L69 3BX, UK
}

${ }^{2}$ LSG2M, CNRS UMR 7584, Ecole des Mines, Parc de Saurupt, 54042 Nancy Cedex, France

(Received 00 Month 200x; in final form 00 Month 200x)

\begin{abstract}
We present an overview of experimental studies of the structure of adsorbed atomic and molecular species on quasicrystal surfaces with a particular focus on those systems where quasiperiodic ordering of the adsorbate structure occurs. Atomic adsorption is illustrated with examples from studies of $\mathrm{Fe}, \mathrm{Si}$ and $\mathrm{Gd}$ adsorption on the five-fold surface of $i$-Al-Pd-Mn. Overlayer structure is correlated with several physical parameters to identify trends. It is concluded that the chemical properties of the adsorbate (metallic radius, electronegativity, melting temperature) are important indicators of quasiperiodic structuring of the adsorbate system. These correlations allow predictions of those elements likely to yield pseudomorphic overlayers. Structural effects upon molecular adsorption on clean quasicrystal surfaces have been less successful. A new approach to ordered molecular adsorption is described and illustrated for $\mathrm{C}_{60}$ adsorption on a $\mathrm{Pb}$ monolayer film on the ten-fold surface of $d$-Al-Ni-Co.
\end{abstract}

\footnotetext{
$\dagger$ Present Address: Department of Chemistry, University of Toronto, Toronto, Ontario M5S 3H6, Canada ${ }^{\ddagger}$ Corresponding author. e-mail: mcgrath@liv.ac.uk; Ph.: +441517943873; Fax: +441517080662
}

\section{Philosophical Magazine}

ISSN 1478-6435 print/ISSN 1478-6443 online (c) 200x Taylor \& Francis

http://www.tandf.co.uk/journals

DOI: 10.1080/1478643YYXxxxxxxx 


\section{Introduction}

The discovery of quasicrystals twenty-five years ago [1] took place at the same time as the maturation of the field of surface science. At that time, new techniques were being developed to study structural, dynamic, electronic and kinetic aspects of surfaces. Of the structural techniques available, many were based on diffraction physics and relied on a periodic formalism for the elucidation of surface structure. The discovery of scanning tunnelling microscopy (STM) in 1981-82 [2] was a major step forward for the field in general. It was also a technique which could be fruitfully applied to quasicrystal surfaces, and the first such experiments took place around 1990 [3]. Since then quasicrystals have provided a fascinating playground for surface and nanoscale scientists, and over the past fifteen years or so, there has been substantial progress in the field.

A key step was the development of protocols for clean surface preparation in vacuum. This is achieved using the conventional surface science technique of sputtering with energetic argon ion beams to remove contaminants followed by annealing to restore atomic order at the surface. The accumulated annealing time for quasicrystals is often tens of hours, much longer than for single crystals. These long annealing times facilitate the complex and poorly understood processes of the re-growth of the quasicrystalline surface following bombardment.

Studies of several clean quasicrystal surfaces have been reported. These include the five-fold surface of $i$-Al-Pd-Mn and the ten-fold surface of $d$-Al-Ni-Co. For these surfaces, a number of facts have been established. Firstly, surfaces may be prepared having large terraces of similar size to those observed in studies of conventional periodic crystal surfaces, e.g. Ref. [4]. Large area scans of the five-fold surface of $i$-Al-Pd-Mn display atomically flat terraces of micron dimensions [4]. Secondly the exposed terraces appear to be terminations corresponding to unreconstructed planes of the bulk structures. The planes exposed tend to be those with the lowest surface energy [5]. Thirdly, atomic resolution images obtained using STM have allowed detailed comparison with models extracted from bulk structures [4]. Often such images can be tiled using Penrose or related tilings, which contributes to structural analysis. Details of this progress have been reported in several reviews [6-8].

In this paper, we focus not on studies of clean quasicrystal surfaces, but on studies of adsorption of atomic and molecular species. There has been significant interest in searching for physical quasiperiodic systems of reduced complexity and dimensionality. The formation of epilayers (epitaxially grown thin films) also offers a route to the exploitation of these materials, because of the possibility of using such epilayers in non-vacuum environments.

\section{Experimental Details}

The samples used in the experiments described in this paper were produced at Ames laboratory. They were mechanically hand polished using 6,1 and 1/4 micron diamond paste. Atomically flat surfaces with large flat terraces was obtained through cycles of $3 \mathrm{keV} \mathrm{Ar}{ }^{+}$sputtering for 45 minutes at room temperature followed by annealing for four hours at a temperature of $940 \mathrm{~K}$ for Al-Pd-Mn and $1070 \mathrm{~K}$ for Al-Ni-Co, at a base pressure of $1.5 \times 10^{-10}$ mbar. The annealing was performed by electron bombardment of the sample. The temperature was monitored through an infra-red pyrometer.

Scanning tunnelling microscopy (STM) was performed in ultra high vacuum (UHV) at a base pressure of $3 \times 10^{-11}$ mbar using an Omicron variable temperature STM. Iron and $\mathrm{Gd}$ and $\mathrm{Pb}$ were deposited using an Omicron EFM-3 electron beam evaporator. The chamber pressure did not exceed $2.5 \times 10^{-10}$ mbar during evaporation. The sample was at room temperature during deposition and measurement. As the coverage was mainly determined from STM observation the deposition and hence coverage are quoted in terms of monolayer equivalent (MLE). One MLE corresponds to the completion of a layer as monitored using STM. The surface order was monitored using LEED, and AES was used to determine sample cleanliness using the LEED apparatus as an analyser in retarding field mode. No post-deposition annealing was carried out in any of the experiments.

The $\mathrm{C}_{60}$ evaporation was performed using a thin $\mathrm{W}$ filament wrapped around a Pyrex crucible containing $\mathrm{C}_{60}$, with temperature regulated using a K-type thermocouple tightly strapped to the crucible. During 
evaporation the $\mathrm{W}$ filament glowed yellow and was approximately $3 \mathrm{~cm}$ away from the sample. Evaporating temperatures in the range $500 \mathrm{~K}-520 \mathrm{~K}$ were used and the chamber pressure did not exceed $4 \times 10^{-10}$ mbar during evaporation.

Auger measurements to determine growth mode for the Fe system were performed in a separate system under a base pressure of $1.5 \times 10^{-10}$ mbar using the same evaporation source. A Perkin Elmer double pass cylindrical mirror analyser operated at a beam energy of $2 \mathrm{keV}$ was used to provide high quality Auger spectra to obtain information about the growth mode.

\section{Adsorption of atomic species}

In this section we discuss the structures adopted by atomic species after adsorption on quasicrystal surfaces. We illustrate the paper with examples of new studies. Using the body of work which has been completed to date, we search for correlations of surface structure the physical properties of the adsorbing species. This leads us to predictions of which elements might form quasiperiodic overlayers.

We first define some terms which are used to describe the relationship of the adsorbate structure to the substrate in heteroepitaxial growth. When the adsorbing species adopts its native structure, but with some orientational relationship to the substrate, then this is classed as rotational epitaxy (RE). Pseudomorphic (P) growth occurs when the adsorbing species adopts a structure which differs from the normal crystalline state and is strongly influenced by the substrate. This is the desired growth mode for the formation of a quasiperiodic single element structure. To date this has only truly been observed for systems up to a monolayer coverage. Occasionally a crystalline multilayer has been found to have a structural modulation (MLM) due to the substrate. Finally, intermixing (I) may occur with the consequent formation of an alloyed species.

\subsection{Groups 3A, 4A and $5 A$}

Aluminium atoms adsorbed on the five-fold surface of $i$-Al-Cu-Fe at low coverages $(\approx 0.04 \mathrm{ML})$ nucleate to form five-fold pseudomorphic "starfish" [9]. The pseudomorphic structure is lost as the coverage increases. Aluminium adsorbed on $i$-Al-Pd-Mn [10] and $d$-Al-Ni-Co [11] results in rotationally epitaxial structures.

Recently it has also been demonstrated that Si adsorbed on both the five-fold surface of $i$-Al-Pd-Mn [12] and $d$-Al-Ni-Co [13] at sub-monolayer coverages up to 0.75 ML occupies unique sites which leads to quasiperiodic ordering. Beyond these coverages disorder sets in. Arsenic adsorbed on the ten-fold surface of $d$-Al-Ni-Co leads to an epitaxial intermixed $\operatorname{AlAs}(111)$ film [14].

The first single element pseudomorphic quasiperiodic monolayers were reported for $\mathrm{Bi}$ and $\mathrm{Sb}$ on the five-fold surface of $i$-Al-Pd-Mn and on the ten-fold surface of $d$-Al-Ni-Co [15]. The growth of a Pb monolayer on $i$-Al-Pd-Mn has provided insight into the link between quasiperiodicity and electronic structure. Lead appears to completely wet the surface and the overlayer structure indicates the formation of a twodimensional quasicrystal [16]. In these circumstances the electronic pseudogap is still observed; indeed it is found to broaden somewhat. This non-metallic behaviour of a metallic element such as $\mathrm{Pb}$ is unique and demonstrates very clearly the interplay between physical properties and quasiperiodic structure. Quasiperiodic monolayers have also been observed using STM for $\mathrm{Sn}$ on $i$-Al-Cu-Fe [17] and $\mathrm{Pb}$ on $d$-Al-Ni-Co [18].

\section{$3.2 \quad$ Transition metals: $\mathrm{Cu}, \mathrm{Ag}, \mathrm{Pt}, \mathrm{Au}$}

An ultra thin film of copper with a quasiperiodic modulation was formed by depositing copper atoms on the clean five-fold surface of $i$-Al-Pd-Mn [19]. The $\mathrm{Cu}$ atoms were found to self-organise into a layered structure using the quasicrystal surface as a template. This can be termed a modulated multilayer. STM work on the deposition of Ag on the five-fold surface of Al-Pd-Mn indicates the formation of high aspect ratio islands which are rotationally epitaxial with the substrate [20], although Shimoda et al. did not find any ordered structure for Ag deposition on either $d$-Al-Ni-Co or $i$-Al-Pd-Mn [21].

Gold was found to form intermixed alloys following deposition on $d$-Al-Ni-Co [22] and $i$-Al-Pd-Mn [23,24] 


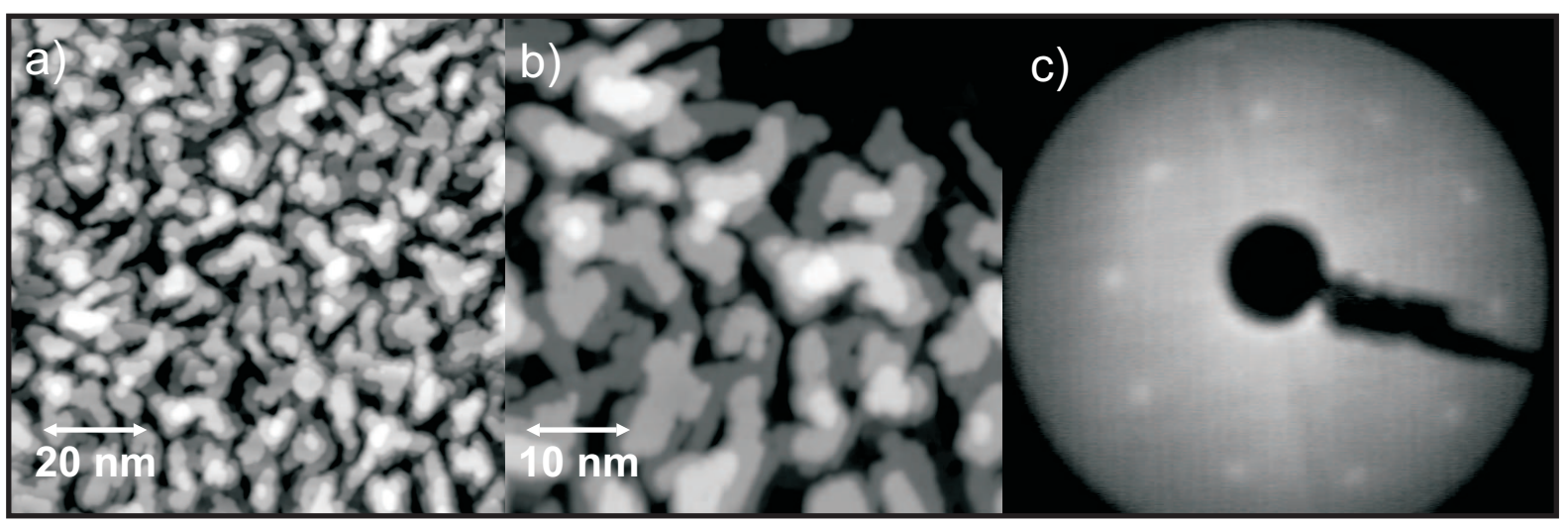

Figure 1. (a) $100 \mathrm{~nm} \times 100 \mathrm{~nm}$ STM image of $9 \mathrm{MLE}$ of Fe on Al-Ni-Co; (b) $50 \mathrm{~nm} \times 50 \mathrm{~nm}$ image of (a); (c) LEED pattern at a beam energy of $120 \mathrm{eV}$. After Ref. [30].

in the presence of in the presence of In acting as a surfactant. Similar behaviour was found for Pt adsorption, again in the presence of $\mathrm{In}$, leading to the formation of multiply twinned $\mathrm{PtAl}_{2}$ crystals $[21,25]$.

\subsection{Ferromagnetic transition metals: $\mathrm{Fe}, \mathrm{Co}, \mathrm{Ni}$}

The formation of thin quasiperiodic films with magnetic properties is of great interest. In bulk quasicrystals such as $i$-Al-Pd-Mn with magnetic elements, only weak magnetic effects have been measured [26]; the behaviour is similar to that observed in spin glasses. The unusual symmetry of quasiperiodic films could give rise to previously unobserved magnetic behaviour.

Cobalt [27] forms row-like structures with a quasiperiodic modulation very similar to that found for $\mathrm{Cu}$ [19]. The structural behaviour of Fe films adsorbed on the five-fold surface of $i$-Al-Pd-Mn has also been investigated. In this case, no pseudomorphic behaviour is found [28]. Using LEED and secondary electron imaging (SEI), Weisskopf and co-workers found that for Ni adsorption on $i$-Al-Pd-Mn an intermixed layer with five domains of a crystalline structure is formed [29].

For Fe on $d$-Al-Ni-Co at room temperature, intermixing is found as evidenced by coverage-dependent Auger electron spectroscopy measurements [30]. These measurements however do not enable a detailed compositional analysis. Initially the intermixed film grows in a layer-by-layer fashion, and the absence of a LEED pattern indicates that these layers are disordered. After about nine monolayers, nanosized multilayer islands are observed (Fig. 1(a,b)). Although not obvious from the STM data, the LEED pattern (Fig. 1(c)) indicates that these islands form five domains which are predominantly aligned along five high symmetry directions rotated by $72^{\circ}$ from each other. The layer thickness was determined to be $0.20 \pm 0.01$ $\mathrm{nm}$ by measuring the step height using line profile analysis. The k-vector of the principal spots in the LEED pattern is estimated at $2.63 \AA^{-1}$, which yields a real-space value of $2.39 \AA$, comparable with the nearest-neighbour distance in bcc Fe of $2.48 \AA$. However it is not possible to link this distance to the geometry of these layers without more detailed compositional and structural information.

\subsection{Rare earth metals: Gd}

There are no previously published studies of the adsorption of rare earth metals on quasicrystal surfaces. Here we present the adsorption of Gd on the five-fold surface of $i$-Al-Pd-Mn. The results for Gd (metallic radius $1.614 \AA$ ) adsorbed at room temperature are shown in Fig. 2. The figure shows the structural development of the film up to a coverage of $3 \mathrm{ML}$. The film develops through the formation of threedimensional clusters, without any indication of ordering in the autocorrelation patterns or fast Fourier transforms of the images. This structural behaviour can be classified as Volmer-Weber type growth. Based on density functional calculations carried at at $0 \mathrm{~K}$, Krajčí and Hafner have predicted that Gd could form an ordered overlayer on $i$-Al-Pd-Mn; therefore it would be interesting to revisit this system with at lower temperatures [31]. The temperature of the substrate is an important parameter in determining the growth 


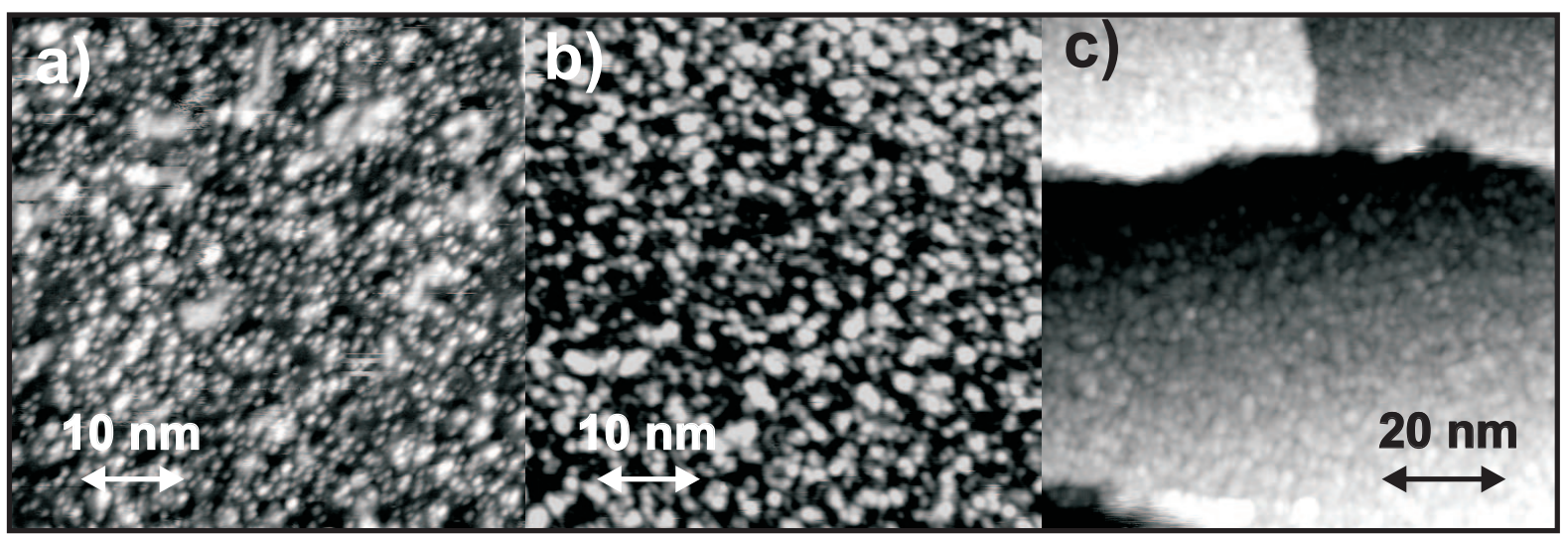

Figure 2. (a) $i$-Al-Pd-Mn following the deposition of $0.3 \mathrm{ML}$ of Gd. The Gd atoms are clearly visible, but no order is discernible using autocorrelation or FFT functions; (b) $0.6 \mathrm{ML}$ of Gd on Al-Pd-Mn; (c) $3 \mathrm{ML}$ of Gd on Al-Pd-Mn. The film exhibits disordered three-dimensional growth.

mode.

\subsection{Group 8 Noble gases: Xe}

LEED studies supported by Monte Carlo calculations indicate that at $77 \mathrm{~K}$, a monolayer of Xe adsorbs on the ten-fold surface of $d$-Al-Ni-Co in an epitaxial fashion [32]. In the second layer the evolution of the bulk hexagonal phase proceeds.

\subsection{Discussion}

Table 1 lists systems where monolayer or thicker films have been deposited on quasicrystal surfaces. The table is sorted first according to the growth mode which is listed in the fifth column, then by atomic number in the second column. The literature reference is given in column four. A number of physical properties are also listed. Atomic radius is an important geometrical parameter and is listed in column six. The Pauling single-bond metallic radius [33] is used as the majority of elements studied are metallic. This is an approximation, as the coordination of adsorbed atoms is likely to be five or greater. However the values do not differ significantly from half of the nearest-neighbour bond-lengths in the elements [34]. An indication of the strength of bonding in the elemental solid is given by the melting temperature and these are listed in column seven [35]. Electronegativity is an important indicator of chemical reactivity. The Pauling electronegativity is listed in column eight [36]. The last column lists the valence electron configuration.

Table 1 reveals some interesting trends. Firstly, $\mathrm{Co}$ and $\mathrm{Cu}$ form modulated multilayer structures at room temperature. In this respect, if the physical parameters listed are of relevance, then on this basis it would be expected that $\mathrm{Ni}$ might also form such a structure. It might be worthwhile to re-investigate $\mathrm{Ni}$ as an adsorbate with STM, under different adsorption conditions - perhaps at low temperature.

Turning to those elements which form pseudomorphic structures, there are also some interesting trends. $\mathrm{Al}$ and $\mathrm{Si}$ adsorb pseudomorphically but at sub-monolayer coverages. Germanium, being chemically very similar to $\mathrm{Si}$ (see Table 2), is likely to form similar sub-monolayer structures. Xenon forms a pseudomorphic layer at low temperatures, followed by a bulk-like film. It would be surprising if other noble gas atoms did not also behave in a similar manner.

$\mathrm{Sn}, \mathrm{Sb}, \mathrm{Pb}$ and $\mathrm{Bi}$ all form complete pseudomorphic monolayers on a variety of Al-based quasiperiodic surfaces. They are all heavy atoms from groups $4 \mathrm{~A}$ and $5 \mathrm{~A}$ of the periodic table whose valence electronic configurations are partially filled $p$ orbitals. The ranges of the numerical parameters for these elements as listed in Table 1 are shown in Equations (1)-(3): 


\begin{tabular}{ccccccccc}
\hline \hline Element & $Z$ & Substrate & Ref. & GM & $r_{P}$ & $T_{M}$ & $\chi_{P}$ & $\mathrm{EC}$ \\
\hline $\mathrm{Co}$ & 27 & $i$-Al-Pd-Mn & {$[27]$} & MLM & 1.157 & 1768 & 1.88 & $4 s_{2}$ \\
& & $d-\mathrm{Al}-\mathrm{Ni}-\mathrm{Co}$ & {$[27]$} & $\mathrm{MLM}$ & & & & \\
$\mathrm{Cu}$ & 29 & $i$-Al-Pd-Mn & {$[19]$} & $\mathrm{MLM}$ & 1.173 & 1358 & 1.90 & $4 s_{1}$ \\
$\mathrm{Gd}$ & 64 & $i$-Al-Pd-Mn & This work & $\mathrm{VW}$ & 1.618 & 1585 & 1.2 & $4 p_{2}$ \\
$\mathrm{Al}$ & 13 & $i$-Al-Pd-Mn & {$[10]$} & $\mathrm{RE}$ & 1.248 & 933 & 1.61 & $3 p_{1}$ \\
& & $d-\mathrm{Al}-\mathrm{Ni}-\mathrm{Co}$ & {$[11]$} & $\mathrm{RE}$ & & & & \\
$\mathrm{Fe}$ & 26 & $i-\mathrm{Al}-\mathrm{Pd}-\mathrm{Mn}$ & {$[28,37]$} & $\mathrm{RE}$ & 1.165 & 1808 & 1.83 & $4 s_{2}$ \\
$\mathrm{Ag}$ & 47 & $i$-Al-Pd-Mn & {$[20]$} & $\mathrm{RE}$ & 1.339 & 1234 & 1.93 & $5 s_{1}$ \\
& & $d-\mathrm{Al}-\mathrm{Ni}-\mathrm{Co}$ & {$[20]$} & $\mathrm{RE}$ & & & & \\
$\mathrm{Fe}$ & 26 & $i-\mathrm{Al}-\mathrm{Ni}-\mathrm{Co}$ & {$[30]$} & $\mathrm{I}$ & 1.165 & 1808 & 1.83 & $4 s_{2}$ \\
$\mathrm{Ni}$ & 28 & $i-\mathrm{Al}-\mathrm{Pd}-\mathrm{Mn}$ & {$[29]$} & $\mathrm{I}$ & 1.149 & 1726 & 1.91 & $4 s_{2}$ \\
$\mathrm{As}$ & 33 & $d-\mathrm{Al}-\mathrm{Ni}-\mathrm{Co}$ & {$[14]$} & $\mathrm{I}$ & 1.21 & 1090 & 2.18 & $4 p_{3}$ \\
$\mathrm{Pt}$ & 78 & $d-\mathrm{Al}-\mathrm{Ni}-\mathrm{Co}$ & {$[21,25]$} & $\mathrm{I}$ & 1.29 & 2041 & 2.28 & $6 s_{1}$ \\
$\mathrm{Au}$ & 79 & $d-\mathrm{Al}-\mathrm{Ni}-\mathrm{Co}$ & {$[22]$} & $\mathrm{I}$ & 1.350 & 1338 & 2.54 & $6 s_{1}$ \\
& & $i-\mathrm{Al}-\mathrm{Pd}-\mathrm{Mn}$ & {$[23,24]$} & $\mathrm{I}$ & & & & \\
$\mathrm{Al}$ & 13 & $i-\mathrm{Al}-\mathrm{Cu}-\mathrm{Fe}$ & {$[9]$} & $\mathrm{P}$ & 1.248 & 933 & 1.61 & $3 p_{1}$ \\
$\mathrm{Si}$ & 14 & $i-\mathrm{Al}-\mathrm{Pd}-\mathrm{Mn}$ & {$[38]$} & $\mathrm{P}$ & 1.175 & 1680 & 1.90 & $3 p_{2}$ \\
& & $d-\mathrm{Al}-\mathrm{Ni}-\mathrm{Co}$ & {$[13]$} & $\mathrm{P}$ & & & & \\
$\mathrm{Xe}$ & 54 & $d-\mathrm{Al}-\mathrm{Ni}-\mathrm{Co}$ & {$[32]$} & $\mathrm{P}$ & & 161 & 2.67 & $5 p_{6}$ \\
$\mathrm{Sn}$ & 50 & $i-\mathrm{Al}-\mathrm{Cu}-\mathrm{Fe}$ & {$[17]$} & $\mathrm{P}$ & 1.399 & 505 & 1.96 & $5 p_{2}$ \\
$\mathrm{Sb}$ & 51 & $d-\mathrm{Al}-\mathrm{Ni}-\mathrm{Co}$ & {$[15]$} & $\mathrm{P}$ & 1.410 & 904 & 2.05 & $5 p_{3}$ \\
& & $i-\mathrm{Al}-\mathrm{Pd}-\mathrm{Mn}$ & {$[15]$} & $\mathrm{P}$ & & & & \\
$\mathrm{Pb}$ & 82 & $i-\mathrm{Al}-\mathrm{Pd}-\mathrm{Mn}$ & {$[16]$} & $\mathrm{P}$ & 1.538 & 601 & 2.33 & $6 p_{2}$ \\
& & $d-\mathrm{Al}-\mathrm{Ni}-\mathrm{Co}$ & {$[18]$} & $\mathrm{P}$ & & & & \\
$\mathrm{Bi}$ & 83 & $i-\mathrm{Al}-\mathrm{Pd}-\mathrm{Mn}$ & {$[15]$} & $\mathrm{P}$ & 1.520 & 545 & 2.02 & $6 p_{3}$ \\
& & $d-\mathrm{Al}-\mathrm{Ni}-\mathrm{Co}$ & {$[15]$} & $\mathrm{P}$ & & & & \\
& & $i-\mathrm{Al}-\mathrm{Cu}-\mathrm{Fe}$ & {$[39]$} & $\mathrm{P}$ & & & & \\
\hline
\end{tabular}

Table 1. A list of experimentally determined growth modes for adsorbed overlayers on Al-based quasicrystal surfaces. GM is the growth mode. $Z$ is the atomic number. $r_{P}$ is the single bond metallic radius in $\AA$ as determined by Pauling [33]. $T_{M}$ is the melting temperature in Kelvin [35]. $\chi_{P}$ is the Pauling electronegativity [36]. EC is the valence electronic configuration. RE - rotational epitaxial growth; VW - Volmer-Weber growth; MLM - modulated multi-layer; P - pseudomorphic growth; I - inter-mixing.

\begin{tabular}{cccccc}
\hline \hline Element & $Z$ & $r_{P}$ & $T_{M}$ & $\chi_{P}$ & $\mathrm{EC}$ \\
\hline $\mathrm{Ge}$ & 32 & 1.22 & 1211 & 2.1 & $4 p_{2}$ \\
& & & & & \\
$\mathrm{Te}$ & 52 & 1.37 & 723 & 2.1 & $5 p_{4}$ \\
$\mathrm{Hg}$ & 80 & 1.44 & 234 & 2.0 & $6 s_{2}$ \\
$\mathrm{Po}$ & 84 & 1.53 & 527 & 2.0 & $5 p_{4}$ \\
\hline \hline
\end{tabular}

Table 2. A list of candidate adsorbate species for the formation of pseudomorphic monolayers, based on the criteria discussed in the text. The parameters are as defined in Table 1. 


$$
\begin{aligned}
1.399 & \leq r_{P} \leq 1.538 \\
505 & \leq T_{m} \leq 904 \\
1.96 & \leq \chi_{P} \leq 2.33
\end{aligned}
$$

An inspection of the periodic table for elements with physical parameters close to these values yields a number of candidates shown in Table 2. Of these, the best match is for Po, although its toxicity and radioactivity preclude it from further investigation. However $\mathrm{Hg}$ and $\mathrm{Te}$ are both easily deposited on surfaces in vacuum and present as excellent candidates for the formation of new pseudomorphic structures on Al-based quasicrystal surfaces.

\section{Molecular adsorption on quasicrystal surfaces}

Molecules adsorbing at a unique site on a quasicrystal surface could form ordered quasiperiodic overlayers by transference of the quasicrystallinity from the substrate 'template' to the adsorbate structure. Such overlayers would be very attractive for comparison with theoretical predictions of their expected symmetries [40], and for the study of a wide range of electronic and dynamic phenomena in two dimensions. The requirements for such ordered adsorption is that there is an appropriate balance between adsorbatesubstrate and adsorbate-adsorbate interactions. If the adsorbate-substrate interaction is too strong, the molecules will not diffuse to find similar adsorption sites. On the other hand, if the adsorbate-adsorbate interaction dominates, the overlayer will adopt a structure characteristic of this interaction and uninfluenced by the substrate potential corrugation.

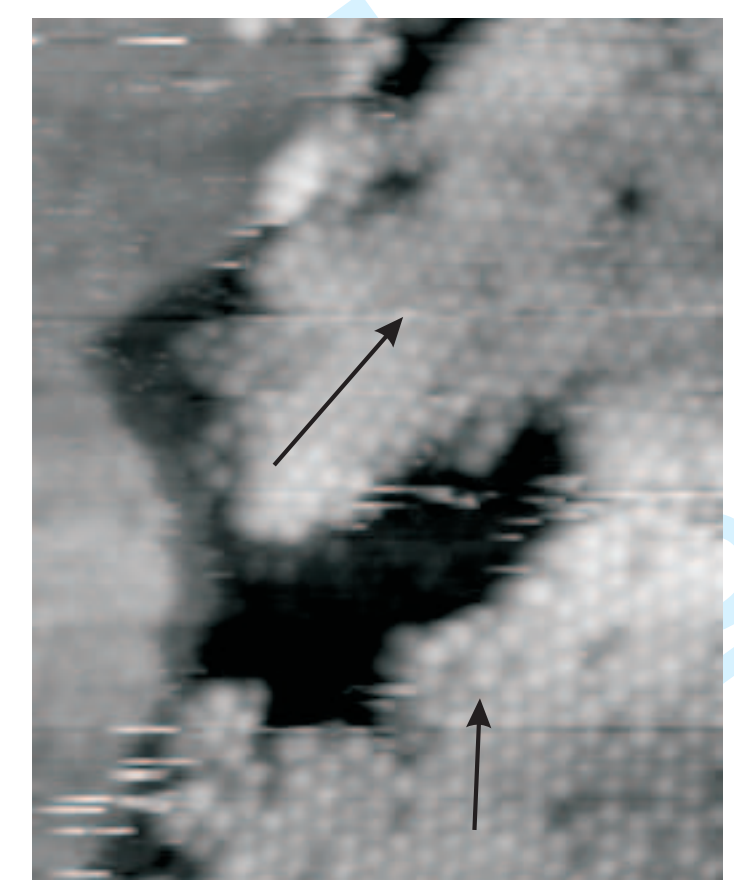

Figure 3. $25 \mathrm{~nm} \times 40 \mathrm{~nm}$ image of $\mathrm{C}_{60}$ molecules adsorbed on a quasiperiodic $\mathrm{Pb}$ film adsorbed on the ten-fold surface of the decagonal Al-Ni-Co quasicrystal. Arrows indicate $\mathrm{C}_{60}$ domain orientations.

Several investigations of molecular adsorption on quasicrystal surfaces have been undertaken. Thiel and co-workers investigated oxygen and water adsorption $[41,42]$ and found that dissociative adsorption takes place. The adsorbed species react aggressively with the substrate destroying the surface order. A similar picture was found for $\mathrm{H}_{2} \mathrm{~S}$ adsorption [43]. Ethylene $\left(\mathrm{C}_{2} \mathrm{H}_{4}\right)$ deposited at room temperature on the ten-fold 
surface of $d$-Al-Ni-Co was found to cause the disappearance of the LEED pattern from the clean surface completely after a $20 \mathrm{~L}$ exposure, indicating disordered adsorption [44]. $\mathrm{C}_{60}$ deposited on $i$-Al-Pd-Mn was found to adsorb intact and preferentially dock in pentagonal hollow sites [45] at low coverages. These STM images reveal that the molecules adsorb in a unique site at the surface and decorate the quasicrystal lattice. This indicates that $\mathrm{C}_{60}$ molecules have a site preference [45]. However it was impossible to determine the exact configuration of the molecules with relation to the substrate in that study, and for higher coverages disordered adsorption was dominant. Few studies have been undertaken at lower temperatures. Benzene $\left(\mathrm{C}_{6} \mathrm{H}_{6}\right)$ was found to adsorb in a disordered manner at the surface of Al-Pd-Mn at $77 \mathrm{~K}$, and completely desorbs from the surface at $150 \mathrm{~K}$ [46].

The recent discoveries of single-element quasicrystalline thin films and overlayers discussed in Section 3 have opened up an alternative route to achieving ordered molecular adsorption using these singleelement systems as templates for ordered molecular adsorption. The problems of differing reactive sites of multi-element surfaces are thus circumvented. Fig. 3 illustrates the adsorption of $\mathrm{C}_{60}$ molecules on a quasiperiodic $\mathrm{Pb}$ film adsorbed on the ten-fold surface of $d$-Al-Ni-Co. The molecules tend to form ordered hexagonal islands; this close-packed structure indicates that the $\mathrm{C}_{60}-\mathrm{C}_{60}$ interaction dominates and that the substrate potential corrugation is too shallow to trap the $\mathrm{C}_{60}$ molecules in a quasiperiodic array. Nevertheless Fast Fourier analysis from this and other similar images indicates that there is a rotational epitaxy relationship between island orientation and the substrate. These results indicate that a way forward may be to tune either the molecular reactivity (through choice of the molecular species) or the substrate potential corrugation (through choice of the interface species).

\section{Conclusions}

Ordering of adsorbed species on Al-based quasicrystal surfaces has been reviewed and illustrated with some recent examples. For atomic species tabulation of known structures along with some pertinent physical parameters allows prediction of those elements likely to lead to pseudomorphic adsorption structures. For molecular adsorption, a new pathway to the formation of ordered molecular species on quasiperiodic substrates is described.

\section{Acknowledgements}

The UK Engineering and Physical Sciences Research Council (EPSRC) grant number EP/D05253X/1 and the European Union Network of Excellence "Complex metallic alloys" Grant number NMP3-CT-2005500145 are thanked for financial support. T.A. Lograsso, A.R. Ross, C.J. Jenks (Ames Laboratory, Iowa, USA) and I.R. Fisher (currently at Stanford University, California, USA) are acknowledged for providing the $i$-Al-Pd-Mn and $d$-Al-Ni-Co samples. 


\section{References}

[1] D. Shechtman, I. Blech, D. Gratias, and J.W. Cahn, Phys. Rev. Lett. 53, 1951 (1984).

[2] G. Binning, H. Rohrer, C. Gerber, and E. Weibel, Phys. Rev. Lett 49, 57 (1982).

[3] A.R. Kortan, R.S. Becker, F.A. Thiel, and H.S. Chen, Phys. Rev. Lett. 64, 200 (1990).

[4] Z. Papadopolos, G. Kasner, R.D. Diehl, J. Ledieu, E.J. Cox, N.V. Richardson, Q. Chen, T.A. Lograsso, A.R. Ross, and R. McGrath, Phys. Rev. B 66, 184207 (2002).

[5] Z. Papadopolos, P. Pleasants, G. Kasner, V. Fournée, C.J. Jenks, J. Ledieu, and R. McGrath, Phys. Rev. B 69, 224201 (2004).

[6] R. McGrath, J. Ledieu, E.J. Cox, and R.D. Diehl, J. Phys.: Condensed Matter 14, R119 (2002).

[7] V. Fournée and P.A. Thiel, J. Phys. D: Appl. Phys. 38, R83 (2004).

[8] H.R. Sharma, M. Shimoda, and A.P. Tsai, Advances in Physics 56, 403 (2007).

[9] T. Cai, J. Ledieu, R. McGrath, V. Fournée, T. Lograsso, A. Ross, and P. Thiel, Surf. Sci. 526, 115 (2003).

[10] B. Bolliger, V.E. Dmitrienko, M. Erbudak, R. Luscher, H.U. Nissen, and A.R. Kortan, Phys. Rev. B 6305, 052203 (2001).

[11] T. Fluckiger, Y. Weisskopf, M. Erbudak, R. Luscher, and A.R. Kortan, Nano Letters 3, 1717 (2003).

[12] J. Ledieu, J.T. Hoeft, D.E. Reid, J.A. Smerdon, R.D. Diehl, N. Ferralis, T.A. Lograsso, A.R. Ross, and R. McGrath, Phys. Rev. B $\mathbf{7 2}, 035420(2005)$.

[13] L. Leung, J. Ledieu, P. Unsworth, T.A. Lograsso, A.R. Ross, and R. McGrath, Surf. Sci. 600, 4752 (2006).

[14] K.J. Franke, P. Gille, K.-H. Rieder, and W. Theis, Phys. Rev. Lett. 99, 036103 (2007).

[15] K.J. Franke, H.R. Sharma, W. Theis, P. Gille, P. Ebert, and K.H. Rieder, Phys. Rev. Lett. 89, 156104 (2002).

[16] J. Ledieu, L. Leung, L.H. Wearing, R. McGrath, T.A. Lograsso, D. Wu, and V. Fournée, arXiv:0712.2790v1 [cond-mat.mtrl-sci] (2008).

[17] H.R. Sharma, M. Shimoda, A.R. Ross, T.A. Lograsso, and A.P. Tsai, Phys. Rev. B 72, 045428 (2005).

[18] J.A. Smerdon, J. Parle, L.H. Wearing, L. Leung, C.J. Jenks, I. Fisher, and R. McGrath, in preparation (2007).

[19] J. Ledieu, J.T. Hoeft, D. Reid, J.A. Smerdon, R.D. Diehl, T.A. Lograsso, A.R. Ross, and R. McGrath, Phys. Rev. Lett. 92, 135507 (2004).

[20] V. Fournée, A.R. Ross, T.A. Lograsso, J.W. Evans, and P.A. Thiel, Surf. Sci. 537, 5 (2003).

[21] M. Shimoda, T.J. Sato, A.P. Tsai, and J.Q. Guo, J. Alloys and Compounds 342, 441 (2002).

[22] M. Shimoda, T.J. Sato, A.P. Tsai, and J.Q. Guo, Phys. Rev. B 62, 11288 (2000).

[23] M. Shimoda, J.Q. Guo, T.J. Sato, and A.P. Tsai, Jpn. J. Appl. Phys. 40, 6073 (2001).

[24] T.C.Q. Noakes, P. Bailey, M. Draxler, C.F. McConville, A.R. Ross, T.A. Lograsso, L. Leung, J.A. Smerdon, and R. McGrath, J. Phys. Cond. Matt. 18, 5017 (2006).

[25] M. Shimoda, T.J. Sato, A.P. Tsai, and J.Q. Guo, Surf. Sci. 507, 276 (2002).

[26] T.J. Sato, H. Takakura, A.P. Tsai, K. Ohoyama, K. Shibata, and K.H. Andersen, Mat. Sci. Eng. A 294, 481 (2000).

[27] J.A. Smerdon, J. Ledieu, J.T. Hoeft, D.E. Reid, L.H. Wearing, R.D. Diehl, T.A. Lograsso, A.R. Ross, and R. McGrath, Phil. Mag. 86, $841(2006)$.

[28] L.H. Wearing, J.A. Smerdon, L. Leung, T.A. Lograsso, A.R. Ross, and R. McGrath, Surf. Sci. 601, 3450 (2007).

[29] Y. Weisskopf, M. Erbudak, J.N. Longchamp, and T. Michlmayr, Surf. Sc. 600, 2592 (2006).

[30] L.H. Wearing, J.A. Smerdon, L. Leung, S.S. Dhesi, J. Ledieu, P. Bencok, I. Fisher, C.J. Jenks, and R. McGrath, J. Phys. Condensed Matter 20, 015005 (2008).

[31] M. Krajčí and J. Hafner, Personal communication .

[32] S. Curtarolo, W. Setyawan, N. Ferralis, R.D. Diehl, and M.W. Cole, Phys. Rev. Lett. 95, 136104 (2005).

[33] L. Pauling, J. Am. Chem. Soc. 69, 542 (1947).

[34] L.E. Sutton, in Special publication No. 18, edited by L.E. Sutton (Chemical Society, London, 1965), pp. Supplement 1956-1959.

[35] A.M. James and M.P. Lord, Macmillan's Chemical and Physical Data (Macmillan, London, 1992).

[36] L.C. Pauling, The nature of the chemical bond and the structure of molecules and crystals, 3 ed. (Cornell University Press, Ithaca, NY, 1960).

[37] Y. Weisskopf, R. Luscher, and M. Erbudak, Surf. Sci. 578, 35 (2005).

[38] J. Ledieu, P. Unsworth, T.A. Lograsso, A.R. Ross, and R. McGrath, Phys. Rev. B 73, 012204 (2006).

[39] V. Fournée, H.R. Sharma, M. Shimoda, A.P. Tsai, B. Unal, A.R. Ross, T.A. Lograsso, and P.A. Thiel, Phys. Rev. Lett. 95, 155504 (2005).

[40] R. Lifshitz, Physica A 232, 633 (1996).

[41] V. Demange, F. Machizaud, J.M. Dubois, J.W. Anderegg, P.A. Thiel, and D.J. Sordelet, J. Alloys and Compounds 342, 24 (2002).

[42] C.J. Jenks, Mat. Res. Soc. Symp. Proc. 553, 219 (1999).

[43] J. Ledieu, V.R. Dhanak, R.D. Diehl, T.A. Lograsso, D.W. Delaney, and R. McGrath, Surf. Sci. 512, 77 (2002).

[44] J.Y. Park, D.F. Ogletree, M. Salmeron, R.A. Ribeiro, P.C. Canfield, C.J. Jenks, and P.A. Thiel, Phys. Rev. B 71, 144203 (2005).

[45] J. Ledieu, C.A. Muryn, G. Thornton, R.D. Diehl, T.A. Lograsso, D.W. Delaney, and R. McGrath, Surf. Sci. 472, 89 (2001).

[46] J.T. Hoeft, J. Ledieu, S. Haq, T.A. Lograsso, A.R. Ross, and R. McGrath, Phil. Mag. 86, 869 (2006). 


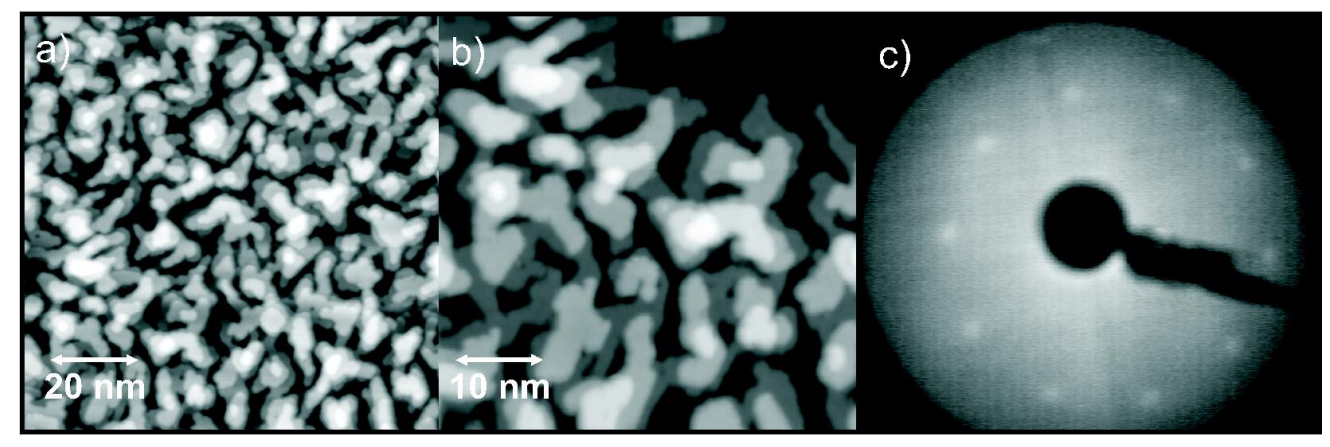

$207 \times 68 \mathrm{~mm}(600 \times 600 \mathrm{DPI})$ 


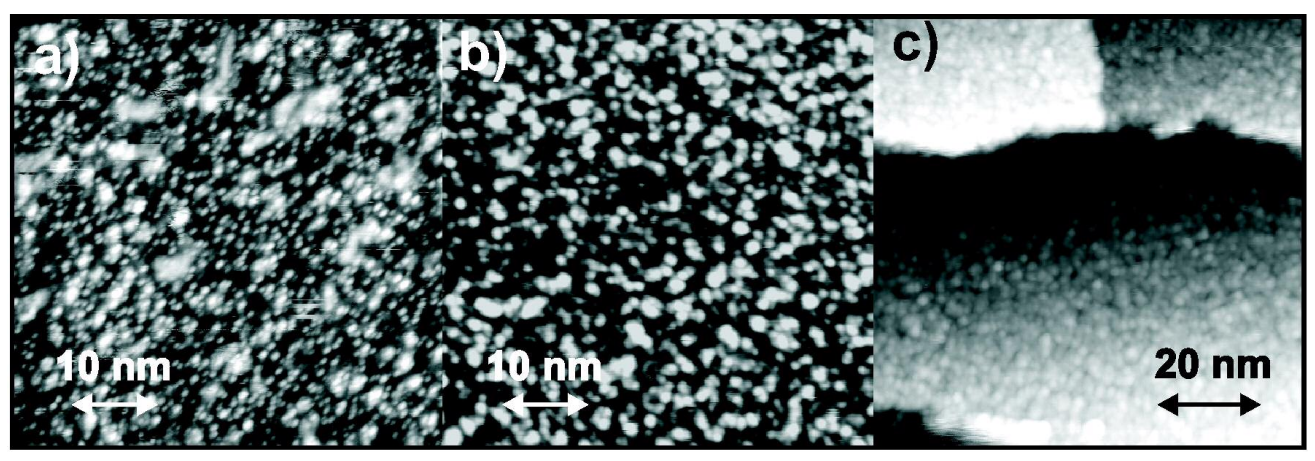

$151 \times 50 \mathrm{~mm}(600 \times 600$ DPI $)$ 


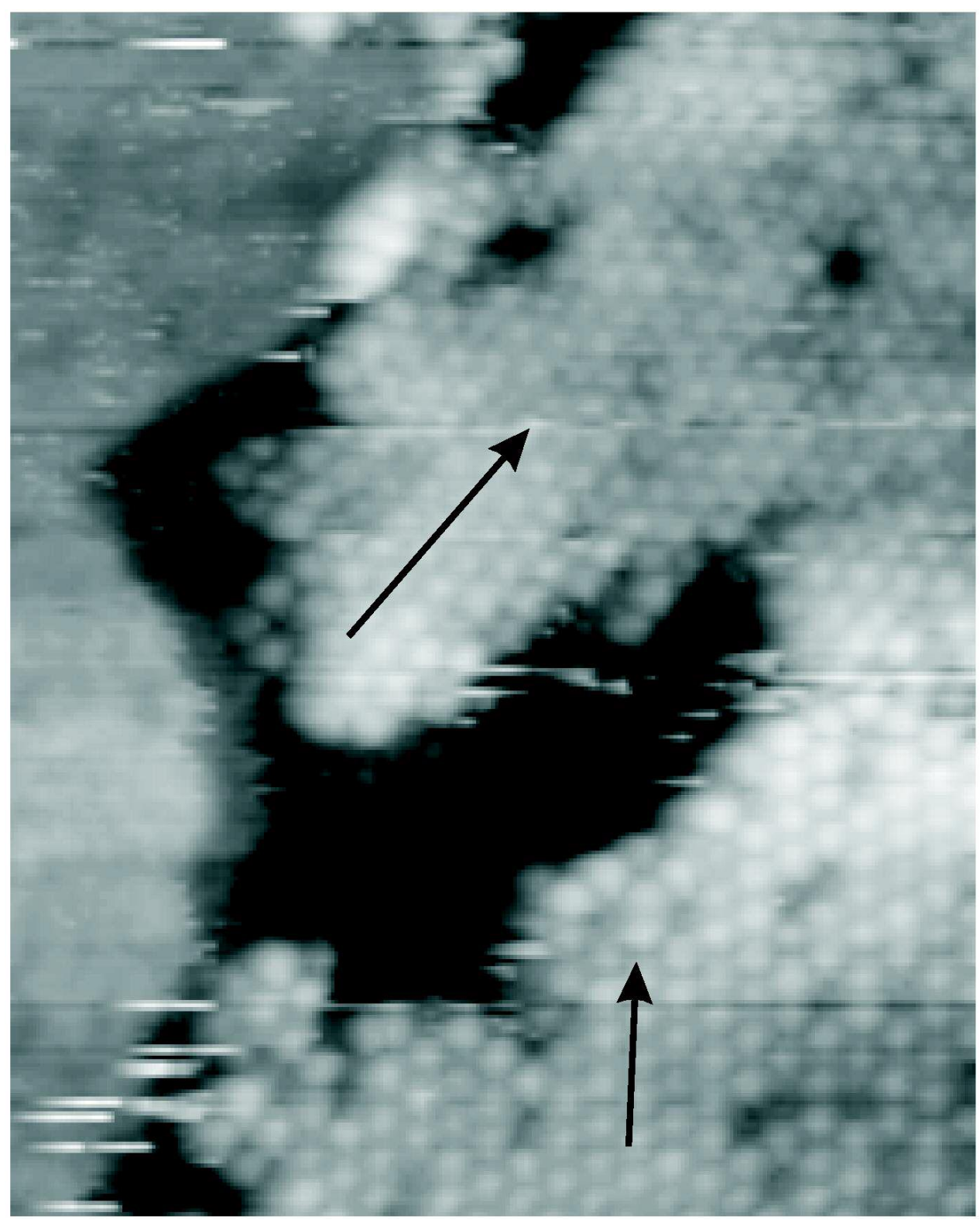

$58 \times 72 \mathrm{~mm}(600 \times 600$ DPI $)$ 